\title{
MOBILE LEARNING SEBAGAI ALTERNATIF PENGEMBANGAN KEPROFESIAN BERKELANJUTAN GURU PROFESIONAL
}

\author{
Hansi Effendi, Yeka Hendriyani \\ Jurusan Teknik Elektro, Fakultas Teknik, Universitas Negeri Padang \\ e-mail : hansieffendi@gmail.com
}

\begin{abstract}
The purpose of this article is to discuss the use of information and communication technologies in the Continuous Professional Development (CPD) for Teachers. CPD simply means learning to help someone fulfill its role in the present or the future more effective, to maintain standards of professional competence, and keep up-to-date with the increasingly competitive job market. This is a form of individual responsibility towards lifelong learning, increasing the level of employability and professional practices, identify and plan to acquire further skills required, planning a career change, and ensure that the professional work standards can be maintained. Mobile learning (m-learning) is a model of learning that utilize information and communication technologies that can be accessed at any time using information technology tools handheld and mobile, such as PDAs, mobile phones, laptops and tablet PCs, is expected to facilitate teachers in carrying out a series of reflective activities designed to increase knowledge, understanding and skills. The learning model is also expected to maintain, improve, and expand the knowledge and skills of teachers and develop their qualities required in their professional lives beyond what they get in basic training they received when they work for the first time. CPD is an absolute need to be done by each individual so that he can work optimally in the profession. In the end it must also be supported by the institution where he/she works, because ideally CPD is an integral part of a person's work and the results will not only benefit the individuals themselves, but also beneficial to the institution where he/she worked. Furthermore, it need to considered about the application of this Agreement that both parties are aware of and try to think of effective ways to increase professionalism in the workplace.
\end{abstract}

Keywords: Mobile Learning, Continuous Professional Development (CPD), Professional Teachers

\begin{abstract}
ABSTRAK
Tujuan artikel ini adalah membahas penggunaan teknologi informasi dan komunikasi dalam Pengembangan Keprofesian Berkelanjutan (PKB) bagi Guru Profesional. PKB secara sederhana berarti belajar yang membantu seseorang memenuhi perannya di masa kini atau masa datang yang lebih efektif, dengan mempertahankan standar kompetensi profesional, dan tetap up-to-date dengan pasar kerja yang semakin kompetitif. Hal ini merupakan wujud tanggung jawab seseorang terhadap pembelajaran sepanjang hayat, meningkatkan tingkat kelayakan kerja dan praktek profesional, mengidentifikasi dan merencanakan untuk memperoleh keterampilan lebih lanjut yang diperlukan, merencanakan perubahan karir, dan memastikan bahwa standar kerja profesional bisa dipertahankan. Mobile learning (m-learning) yang merupakan model pembelajaran yang memanfaatkan teknologi informasi dan komunikasi yang dapat di akses setiap saat menggunakan perangkat teknologi informasi genggam dan bergerak, seperti PDA, telepon genggam, Laptop dan tablet PC, diharapkan dapat memfasilitasi Guru dalam melaksanakan serangkaian aktivitas reflektif yang dirancang untuk meningkatkan pengetahuan, pemahaman, dan keterampilannya. Model pembelajaran ini diharapkan juga dapat memelihara, memperbaiki, dan memperluas pengetahuan dan keterampilan Guru, dan mengembangkan kualitas diri mereka yang diperlukan dalam kehidupan profesional mereka di luar dari yang mereka dapatkan dalam pelatihan dasar yang mereka terima ketika pertama kali bekerja. PKB merupakan hal yang mutlak perlu dilakukan oleh setiap individu agar dia dapat bekerja secara maksimal pada profesinya. Pada akhirnya hal ini haruslah juga didukung oleh institusi tempat dia bekerja, karena idealnya PKB merupakan bagian integral dari pekerjaan seseorang dan hasilnya tidak saja bermanfaat bagi individu itu sendiri, tetapi juga bermanfaat bagi institusi tempat dia bekerja. Sehingga perlu dipikirkan lebih jauh tentang aplikasi PKB ini agar kedua belah pihak menyadari dan mencoba memikirkan cara efektif untuk meningkatkan profesionalisme di tempat kerja.
\end{abstract}

Kata Kunci: Mobile Learning, Pengembangan Keprofesian Berkelanjutan (PKB), Guru Profesional 


\section{PENDAHULUAN}

Belajar adalah aktifitas sepanjang hayat (life-long learning). Seseorang belajar ketika dia belum sekolah, ketika menempuh pendidikan dasar, menengah, sampai menempuh pendidikan tinggi, bahkan ketika telah bekerja/ menekuni suatu profesi tertentu. Ketika kita belajar pada saat kita telah menekuni suatu profesi atau telah bekerja, pembelajaran yang kita lakukan dikenal dengan istilah Continuous Professional Development (CPD) atau istilah dalam Bahasa Indonesia yaitu Pengembangan Keprofesian Berkelanjutan (PKB).

PKB secara sederhana berarti belajar, yang membantu seseorang memenuhi perannya di masa kini atau masa depan yang lebih efektif, dengan mempertahankan standar kompetensi profesional, dan tetap up-to-date dengan pasar kerja yang semakin kompetitif [1]. Ini adalah proses untuk terus belajar di arena profesional seseorang selama dia bekerja dalam profesi itu [2]. Hal ini biasanya terdiri dari kombinasi kegiatan formal dan informal seperti kursus di lembaga pelatihan pendidikan, konferensi, partisipasi dalam komite, dan belajar mandiri.

Tujuan dari PKB yaitu: (1) tanggung jawab seseorang terhadap pembelajaran sepanjang hayat (life-long learning), (2) meningkatkan tingkat kelayakan kerja dan praktek profesional, (3) mengidentifikasi dan merencanakan untuk memperoleh keterampilan lebih lanjut yang diperlukan, (4) merencanakan perubahan karir, dan (5) memastikan bahwa standar kerja profesional bisa dipertahankan. Secara keseluruhan, PKB merupakan investasi masa depan bagi seseorang.

Beberapa manfaat PKB yaitu: (1) kepuasan kerja meningkat karena seseorang bekerja secara maksimal; (2) meningkatkan keamanan di bidang profesional, dan (3) peningkatan pendapatan karena dengan tingkat keterampilan yang lebih tinggi menghasilkan gaji lebih tinggi.

Walaupun banyak memiliki manfaat, PKB juga memiliki keterbatasan, diantaranya: (1) waktu (masalah terbesar), karena akibat kesibukannya, seseorang sering mengatakan bahwa dia kekurangan waktu, sehingga menjadi masalah untuk bisa terus belajar; (2) kurangnya dukungan dari badan profesional; (3) badan profesional masih berorientasi input; (4) masih bermodus box-ticking sehingga PKB menjadi pekerjaan birokrasi; (5) resources - beberapa pengembangan membutuhkan biaya; dan (6) geografi - beberapa penelitian menyebutkan sejumlah orang mengeluh akan jauhnya tempat tinggal mereka dengan tempat diadakannya pertemuan profesional sehingga mereka tidak bisa hadir.
Hal ini juga terjadi pada Guru. Konsekuensi dari guru sebagai profesi adalah Guru harus melaksanakan kegiatan yang menunjang profesinya, yang pada Permenpan no 16 tahun 2009 tentang Jabatan Fungsional Guru dan Angka Kreditnya, PKB Guru terdiri dari 3 sub unsur: (1) melaksanakan pengembangan diri, (2) melaksanakan publikasi ilmiah, dan (3) melaksanakan karya inovatif.

Perkembangan teknologi informasi dan komunikasi (TIK) yang pesat dalam bidang pembelajaran seharusnya dapat mengatasi beberapa keterbatasan yang ada pada pengimplementasian PKB. Artikel ini bertujuan untuk membahas penggunaan TIK dalam PKB, khususnya bagi Guru Profesional.

\section{DISKUSI}

2.1. Pengembangan Keprofesian Berkelanjutan (PKB) dan Profesi Guru

Berdasarkan hasil survey badan pengembangan profesionalisme Inggris, kebanyakan pekerja tidak melihat diri mereka sendiri sebagai pembelajar, dan merasa bahwa pengembangan professional mereka adalah tanggung jawab instansi/ perusahaan tempat mereka bekerja, sedangkan sebagian besar perusahaan atau instansi melihat bahwa pembelajaran sebagai sesuatu yang memiliki nilai individual dan merupakan tanggung jawab pekerja itu sendiri untuk memgembangkan kompetisi pribadinya di pasar kerja. Hal ini mengisyaratkan bahwa agar PKB dapat berjalan dengan baik, kedua belah pihak harus melihat manfaat dari PKB itu sendiri.

Sehingga dalam aplikasinya, PKB harus menjadi bagian integral dari praktek kerja untuk memantau pembelajaran seseorang, fokus pada outputs/outcomes, memanfaatkan keahlian para profesional lain, terutama di mana mereka dapat menunjukkan cara pintas dalam pembelajaran, dan jangan biarkan kegiatan belajar dibatasi oleh profesi; banyak keterampilan dan kemampuan yang relevan dapat diperoleh dengan melihat pembelajaran pada area lain.

Terkait dengan profesi Guru, salah satu komponen penting dalam sistem pendidikan nasional adalah pendidik dan tenaga kependidikan. Komponen pendidik dan tenaga kependidikan merupakan salah satu dari masukan instrumental (intrumental input), di samping kurikulum dan fasilitas pendidikan. Tinggi rendahnya mutu pendidikan sangat ditentukan oleh mutu pendidik dan tenaga kependidikan. Terkait dengan mutu pendidik dan tenaga kependidikaan inilah maka UU Nomor 14 Tahun 2005 tentang Guru dan Dosen mempersyaratkan bahwa "guru wajib memiliki kualifikasi akademik, kompetensi, sertifikat pendidik, sehat jasmani dan rohani, serta memiliki kemampuan untuk mewujudkan tujuan pendidikan nasional". Kualifikasi akademik yang dimaksud 
adalah program S1 atau D-IV. Konsekuensi dari guru sebagai profesi adalah Guru harus melaksanakan kegiatan yang menunjang profesinya dalam program pemerintah yang dikenal dengan Pengembangan Keprofesian Berkelanjutan (PKB).

\subsection{Mobile Learning}

Mobile learning (m-learning) merupakan model pembelajaran yang memanfaatkan teknologi informasi dan komunikasi yang dapat di akses setiap saat menggunakan perangkat teknologi informasi genggam dan bergerak. Contohnya yaitu PDA, telepon genggam, Laptop dan tablet PC.

\subsubsection{Klasifikasi M-learning}

M-learning dapat dikelompokkan dalam beberapa klasifikasi tergantung dari beberapa sudut pandang [3]. Dari sisi teknologi yang digunakan, maka m-learning dapat diklasifikasi berdasar indikator utama, yaitu tipe perangkat yang didukung dan tipe komunikasi nirkabel yang digunakan untuk mengakses materi pembelajaran maupun informasi administratif.

Dari sudut pandang teknologi pengajaran maka m-learning dapat diklasifikasikan berdasar indikator dukungan pembelajaran asynchronous dan atau synchronous, dukungan $e$ learning standar, ketersediaan koneksi internet permanen antara sistem dan pengguna, lokasi pengguna serta layanan akses ke materi pembelajaran dan/atau administrasi.

Menurut waktu dari pengajar dan siswa berbagi informasi, m-learning dapat diklasifikasi menjadi sistem yang mendukung pembelajaran synchronous, sistem yang mendukung pembelajaran asynchronous, dan sistem yang mendukung pembelajaran synchronous dan asynchronous sekaligus.

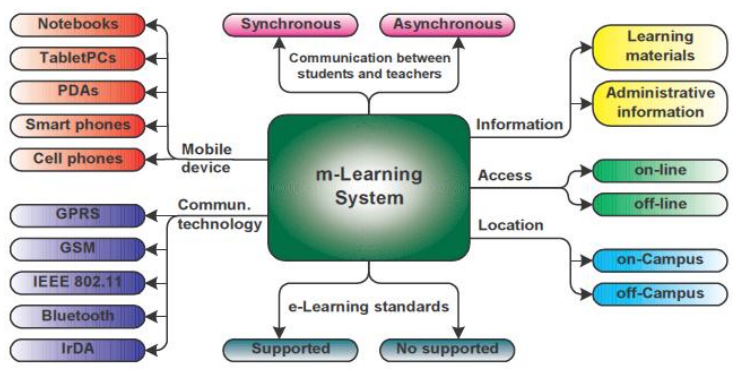

Gambar 1. Klasifikasi Umum Sistem M-learning (Sumber: Georgieva, 2005)

\subsubsection{Aspek Rancangan M-learning}

Karakteristik perangkat maupun pengguna m-learning yang khusus dan unik memerlukan disain yang juga khusus. Sistem e-learning yang ada sekalipun tidak dapat dengan begitu saja ditransfer ke lingkungan m-learning.
Keterbatasan divais pembelajaran dalam $m$ learning memerlukan perhatian dan pertimbangan yang khusus dalam membuat sebuah rancangan aplikasi m-learning. Beberapa aspek yang menjadi perhatian dalam merancang aplikasi m-learning adalah sebagai berikut ${ }^{[4]}$.

a. Keterbatasan Hardware. Perangkat bergerak memiliki computing resources yang terbatas.

b. Keterbatasan Jaringan. Jaringan seluler relatif lambat, tak dapat diandalkan dan tidak aman.

c. Divais yang Pervasif. Perangkat bergerak memiliki bentuk kecil yang beragam dan dapat selalu dibawa ke mana-mana oleh pengguna dan dengan mudah berpindah tangan sehingga menjadi merupakan persoalan yang lebih rumit, baik persoalan sosial maupun persoalan teknis.

d. Skema Integrasi. Banyak aplikasi nirkabel bergerak yang membutuhkan integrasi dengan sistem back-end atau middleware berbeda.

e. Kenyamanan Pengguna. Merancang aplikasi yang nyaman digunakan dan sesuai karakteristik pengguna merupakan tantangan besar bagi para pengembang. Perlu dibuat rancangan yang mudah dan nyaman digunakan pengguna.

Karena beberapa keterbatasan itu maka pengembangan aplikasi m-learning harus mempertimbangkan materi yang harus dibuat. Pada aplikasi m-learning sebaiknya tidak terlalu banyak dijejali materi/informasi dalam satu saat. Materi hendaknya dipecah menjadi materi dengan unit kecil yang disebut chunk. Setiap materi dalam chunk ini dapat dipelajari terpisah dan tidak terlalu bergantung dengan materi di chunk yang lain namun tetap dapat saling berkaitan atau berurutan. Dengan mempelajari materi dalam satu chunk pembelajar dapat memahami satu materi yang utuh, meskipun dalam topik yang kecil.

\subsubsection{Potensi Pemanfaatan}

M-learning merupakan paradigma yang masih relatif baru sehingga belum banyak implementasi $m$ learning yang telah diterapkan. Namun, beberapa potensi m-learning dapat dimanfaatkan untuk membantu dalam proses pembelajaran. Beberapa potensi tersebut di antaranya:

a. Sebagai alternatif buku/komputer (mobile $e$ book). Saat ini sudah banyak perangkat mobile yang memiliki kapabilitas yang cukup untuk diinstal aplikasi, misalnya Java Midlet. Aplikasi mobile yang berfungsi sebagai mobile ebook dapat dimanfaatkan sebagai pengganti buku atau e-book yang praktis digunakan dimanapun dan kapanpun.

b. Sebagai perangkat pencari (knowledge searching tool). Perangkat mobile yang telah terkoneksi internet dapat dimanfaatkan sebagai tool untuk melakukan pencarian informasi atau pengetahuan yang praktis. Hampir apapun 
informasi dapat dicari di internet melalui search engine, seperti Google, secara mobile.

c. Perangkat mobile juga dapat dimanfaatkan sebagai alat bantu pembelajaran. Ada beberapa perangkat yang sudah memiliki kemampuan built-in atau dapat diinstal aplikasi tambahan.)

d. Sebagai learning utility. Perangkat mobile dapat dimanfaatkan sebagai alat bantu pembelajaran seperti kamus, kalkulator, voice recorder, miniensiklopedi, edugame dll. Aplikasi semacam ini dapat diinstal di perangkat seluler atau, dalam beberapa perangkat, sudah diinstal secara built-in.

e. Sebagai perangkat interaksi dan kolaborasi. Perangkat mobile yang telah terkoneksi dengan internet merupakan perangkat yang menarik untuk digunakan sebagai media interaksi dan kolaborasi dalam konteks pembelajaran. Beberapa layanan internet untuk microblogging dan social networking semisal Twitter dan Facebook merupakan layanan yang cukup potensial untuk dimanfaatkan.

2.3. Mobile Learning dan Pengembangan Keprofesian Berkelanjutan (PKB)

PKB merupakan investasi masa depan bagi seseorang. Hal ini biasanya terdiri dari kombinasi kegiatan formal dan informal seperti kursus di lembaga pelatihan pendidikan, konferensi, partisipasi dalam komite, dan belajar mandiri. Banyak sekali manfaat yang akan dirasakan oleh Guru jika mereka mau mengupdate ilmunya dan mau melakukan aktivitas yang berhubungan dengan pengembangan kompetensi profesinya. Tetapi walaupun banyak memiliki manfaat, PKB juga memiliki keterbatasan-keterbatasan.

Dalam rangka mengatasi keterbatasanketerbatasan ini, m-learning dapat dijadikan sebagai alternatif dalam pembelajaran Guru, terutama sekali terkait pembelajaran mandiri. Beberapa keterbatasan yang mungkin diatasi dengan menggunakan m-learning yaitu: waktu, sumber daya, dan geografi.

Pemanfaatan m-learning dapat mengatasi masalah waktu, dimana karena kesibukannya, Guru merasa kekurangan waktu, sehingga menjadi masalah untuk bisa terus belajar. Masalah sumber daya dan letak juga dapat diatasi karena dengan m-learning, karena dengan m-learning sumber informasi dapat didistribusikan dan didapatkan secara luas dan tanpa membutuhkan biaya yang besar serta Guru dapat mendapatkan informasi kapan saja dan dimana saja.

\section{KESIMPULAN}

a. Pengembangan Keprofesian Berkelanjutan (PKB) merupakan hal yang mutlak perlu dilakukan oleh setiap individu agar dia dapat bekerja secara maksimal pada profesinya

b. Aktivitas PKB harus didukung oleh pihak perusahaan/ institusi tempat dia bekerja, karena idealnya PKB merupakan bagian integral dari pekerjaan seseorang.

c. Pada dasarnya PKB tidak saja bermanfaat bagi individu itu sendiri, tetapi juga bermanfaat bagi perusahaan/institusi tempat dia bekerja.

d. Perlu dipikirkan lebih jauh tentang aplikasi PKB agar pihak-pihak yang terlibat menyadari dan mencoba memikirkan cara efektif untuk meningkatkan profesionalisme pekerja di tempat kerja.

e. Mobile learning dapat menjadi alternatif bagi Guru dalam kegiatan Pengembangan Keprofesian Berkelanjutannya.

\section{REFERENSI}

[1] The Association of Professional Engineers and Geoscientists of BC. Continuing Professional Development Guideline. Burnaby. (Available online: www.apeg.bc.ca), (--).

[2] Cunningham, Ian, Graham Dawes, and Ben Bennett. The Handbook of Work Based Learning. Gower Publishing Company, (2004).

[3] Georgieva, Smrikarov, dkk. A General Classification of Mobile Learning System. International Conference on Computer Systems and Technologies: hal 1-3, (2005).

[4] Juntao Yuan, Michael, Enterprise J2ME: Developing Mobile Java Applications, Prentice Hall, (2004).

[5] Kemendiknas. Pedoman pengelolaan Pengembangan Keprofesian Berkelanjutan (PKB). Jakarta: Dirjen Peningkatan Mutu Pendidik dan Tenaga Pendidikan, (2010).

[6] --. Continuing Professional Development. Wikipedia, (Available online: (http://en.wiki pedia.org/wiki/Continuing_professional devel opment), (2011). 